\title{
Jumlah Timbulan dan Komposisi Sampah di Kelurahan Pahandut Kota Palangka Raya serta Dampaknya terhadap Kualitas Air Lindi
}

\author{
Nani Apriyani ${ }^{1, *}$, Rudy Yoga Lesmana ${ }^{2}$ \\ ${ }^{1,2}$ Program Studi Teknik Lingkungan Universitas Muhammadiyah Palangkaraya \\ ${ }^{*}$ Surel: nani.apriyani@umpalangkaraya.ac.id
}

\begin{abstract}
ABSTRAK
Jumlah timbulan sampah akan semakin banyak setiap tahunnya seiring dengan meningkatnya pertumbuhan penduduk. Tempat penampungan sementara (TPS) sampah di daerah pemukiman dapat menimbulkan masalah lingkungan jika tidak dikelola dengan baik. Penelitian ini bertujuan untuk mendapatkan informasi tentang jumlah timbulan sampah dan komposisinya serta tingkat pencemaran kualitas air tanah di sekitar TPS. Penelitian ini menggunakan beberapa metode untuk mendapatkan data primer dan sekunder yang diperlukan yaitu studi literatur, survei lapangan, wawancara serta analisis lapangan dan analisis di laboratorium. Sampel air tanah diambil dari 3 titik pada pemukiman masyarakat. Hasil penelitian menunjukkan jumlah timbulan sampah di TPS Unit Pelaksana Teknis (UPT) Pengelolaan Sampah Terpadu (PST) adalah 77,14 m3/hari atau 12342,4 $\mathrm{kg}$ per hari dengan komposisi meliputi sisa makanan, plastik, kertas, kain tekstil, kayu ranting daun, karet kulit dan logam. Pengujian kualitas air lindi menunjukkan bahwa nilai parameter TSS tidak memenuhi baku mutu, serta konsentrasi minyak dan lemak tidak terdeteksi.
\end{abstract}

\section{Kata kunci}

TPS

timbulan sampah komposisi sampah lindi

\section{PENDAHULUAN}

Pertumbuhan penduduk dan peningkatan kondisi ekonomi masyarakat Indonesia saat ini tanpa kita sadari telah menyebabkan semakin menurunnya kualitas lingkungan hidup. Penurunan kualitas lingkungan hidup dapat kita lihat dari banyaknya kondisi lingkungan yang mengalami degradasi atau penurunan kualitas lingkungan yang diakibatkan oleh adanya pencemaran lingkungan dimana-mana. Pencemaran yang terjadi di lingkungan kita saat ini sedikit banyak dipengaruhi oleh kurangnya kesadaran masyarakat dalam menjaga kualitas lingkungan, salah satu contohnya yaitu, semakin meningkatnya kasus pencemaran air tanah yang diakibatkan oleh jumlah timbulan sampah yang semakin meningkat hasil dari kegiatan sehari-hari masyarakat di beberapa wilayah di Indonesia. Harmayani (2007) mengemukakan bahwa kualitas dan kuantitas air tanah pada daerah permukiman harus terjamin agar dapat digunakan untuk keperluan hidup sehari-hari bagi masyarakat sesuai dengan standar kesehatan dan baku mutu kualitas air. Pembuangan limbah domestik (sampah) di daerah permukiman sangat berpotensi dalam proses pencemaran air tanah, dan sebaiknya harus dilakukan pembuatan sistem jaringan 
pembuangan limbah yang dapat menampung dan mengalirkan limbah tersebut secara baik dan benar agar potensi pencemran air tanah dapat diminimalisir.

Pada kondisi sekarang ini, jumlah timbulan sampah di Tempat Pemrosesan Akhir (TPA) sampah akan terus meningkat, dan apabila tidak tidak diimbangi dengan adanya kegiatan pengolahan dan pemanfaatan sampah di tingkat masyarakat, maka dikhawatirkan akan berpotensi menimbulkan pencemaran air tanah, dan oleh karena itu dibutukan adanya kegiatan pengelolaan sampah untuk mengurangi beban TPA yang dilakukan mendekati sumber sampah, salah satunya di Tempat Penampungan Sementara (TPS) Sampah (Rahmaniah, 2013).

Pada prinsipnya jumlah timbulan sampah di TPS berpotensi mencemari air tanah, karena diakibatkan adanya air lindi yang keluar dari sampah tersebut. Air lindi merupakan air yang terbentuk dalam timbunan sampah yang melarutkan banyak senyawa sehingga memiliki kandungan pencemar yang sangat tinggi, khususnya zat organik. Cairan tersebut mengisi rongga pada sampah yang bila kapasitasnya melampaui kapasitas tekanan air dari sampah, maka cairan tersebut akan keluar dan mengekstraksi bahan organik dan anorganik hasil proses físika, kimia dan biologis (Pinem, 2014).
Kondisi saat ini menyebutkan bahwa timbulan sampah di Kota Palangka Raya mencapai 119,1 ton per hari, sedangkan yang mampu diangkut ke TPA hanya sekitar 57 ton per hari (Disciptarum Kota Palangka Raya). Dengan jumlah timbulan sampah tersebut, maka akan sangat berbahaya jika saat ini tidak dilakukan identifikasi terhadap kualitas air lindi yang berpotensi menimbulakan pencemaran air tanah. Prakiraan timbulan sampah serta komposisinya merupakan dasar perencanaan, perancangan dan pengkajian sistem pengelolaan persampahan. Hal ini dilakukan agar dapat dijadikan pertimbangan bagi stakeholder untuk pengambilan keputusan dikemudian hari, dalam rangka pencegahan dan mitigasi bahaya pencemaran air tanah di kota Palangka Raya.

\section{METODE PENELITIAN}

\section{Lokasi Penelitian}

Lokasi penelitian terdiri dari dua lokasi, yaitu penelitian di lapangan dan penelitian di laboratorium. Penelitian lapangan yaitu pemeriksaan jumlah timbulan sampah, pengambilan sampel air lindi dan pemeriksaan $\mathrm{pH}$ dilakukan di Unit Pelaksana Teknis (UPT) Pengelolaan Sampah Terpadu (PST) Kelurahan Pahandut Kota Palangka Raya, sedangkan penelitian di laboratorium dilakukan di Laboratorium Fakultas Teknik Universitas Muhammadiyah Palangkaraya

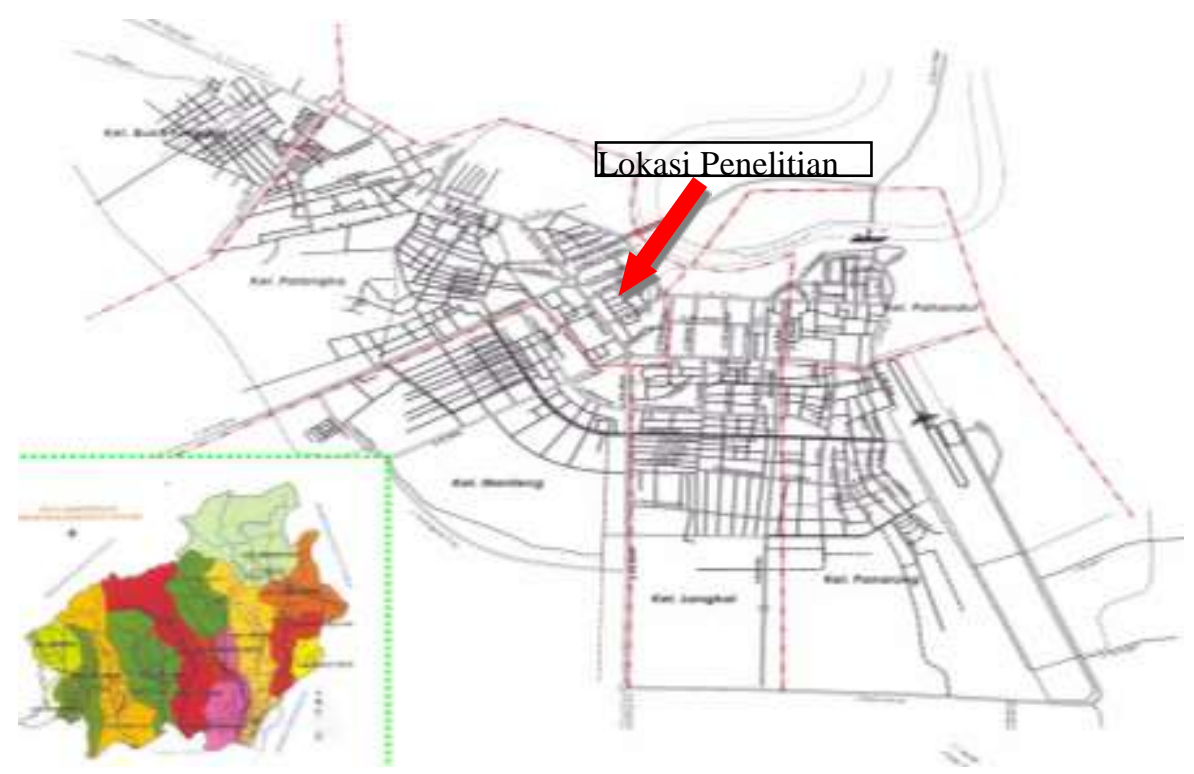

Gambar 2. Peta kecamatan di Kota Palangkaraya

Sumber: Dinas Cipta karya dan Perumahan Kota Palangka Raya, 2013 


\section{Waktu Penelitian}

Penelitian dilakukan pada bulan Januari sampai Februari 2018.

\section{Prosedur Kerja}

Prosedur kerja yang dilakukan terdiri dari penentuan jumlah timbulan dan komposisi sampah serta pemeriksaan sampel air lindi, dengan penjelasan sebagai berikut.

a. Penentuan komposisi dan timbulan sampah

Penentuan komposisi dan timbulan sampah berdasarkan prosedur SNI 193983-1995 berdasarkan data jumlah penduduk. Secara umum besarrnya timbulan sampah dapat diperkirakan berdasarkan klasifikasi kota dan karakteristik sumber sampah.

- Kota sedang adalah kota yang jumlah penduduknya 100.000 - 500.000 jiwa

- Kota kecil adalah kota yang jumlah penduduknya $<100.000$ jiwa

Besaran timbulan sampah berdasarkan klasifikasi kota kemudian ditentukan dalam Tabel 1 berikut.

Tabel 1. Besaran timbulan sampah berdasarkan klasifikasi kota

\begin{tabular}{lcc}
\hline $\begin{array}{c}\text { Klasifikasi } \\
\text { Kota }\end{array}$ & $\begin{array}{c}\text { Volume } \\
\text { (L/orang/hari) }\end{array}$ & $\begin{array}{c}\text { Berat } \\
\text { (kg/orang/hari) }\end{array}$ \\
\hline Kota sedang & $2.75-3.25$ & $0.70-0.80$ \\
Kota kecil & $2.5-2.75$ & $0.625-0.70$ \\
\hline
\end{tabular}

b. Pengambilan sampel air lindi

Pengambilan sampel air lindi dilakukan di kolam penampungan air lindi di TPS.

c. Pemeriksaan sampel air lindi

Pemeriksaan sampel air lindi dilakukan secara langsung di lapangan dan di laboratorium. Pemeriksaan langsung di lapangan dilakukan untuk parameter $\mathrm{pH}$, sedangkan pemeriksaan di laboratorium dilakukan untuk parameter TDS, TSS, DO serta minyak dan lemak.

d. Analisis hasil pemeriksaan sampel air lindi

Hasil pemeriksaan sampel air lindi dianalisis dengan membandingkannya terhadap nilai baku mutu. Pada Peraturan Menteri Lingkungan Hidup dan Kehutanan Republik Indonesia Nomor P.59 / Menlhk / Setjen / Kum.1/7/ 2016 tentang Baku Mutu Lindi bagi Usaha dan/atau Kegiatan Tempat Pemrosesan Akhir Sampah.

\section{HASIL DAN PEMBAHASAN Jumlah Timbulan Sampah}

Timbulan sampah merupakan volume sampah atau berat sampah yang di hasilkan dari jenis sumber sampah diwilayah tertentu persatuan waktu (Departemen PU, 2004). Menurut SNI 19-3964-1995. Timbulan sampah sangat diperlukan untuk menentukan dan mendesain peralatan yang digunakan dalam transportasi sampah, fasilitas recovery material, dan fasilitas Lokasi Pembuangan Akhir (LPA) sampah. Untuk menentukan timbulan sampah, pada umumnya dipakai ukuran volume $\left(\mathrm{m}^{3} /\right.$ hari) atau ukuran berat sampah (ton/hari).

Perhitungan besaran timbulan sampah berdasarkan klasifikasi kota dapat dilihat pada Tabel 1 berdasarkan SNI 19-3983-1995. Jumlah penduduk Kelurahan Pahandut berdasarkan data Badan Pusat Statistik Tahun 2018 di Kelurahan Pahandut dalam Angka Tahun 2018 sebanyak 30.856 jiwa. Berdasarkan data tersebut, dapat diperkirakan jumlah timbulan sampahnya pada Tabel 2 .

Tabel 2. Jumlah timbulan sampah di Kelurahan Pahandut Kota Palangka Raya Tahun 2018

\begin{tabular}{lc}
\hline & Jumlah timbulan sampah \\
\hline Penduduk Total & 30.856 \\
l/org/hari & 2,50 \\
Total $\mathrm{m}^{3} /$ hari & 77,14 \\
$\mathrm{~kg} / \mathrm{org} / \mathrm{hari}$ & 0,40 \\
Total kg/hari & 12342,4 \\
Terlayani & 30.856 \\
Total m /hari & 77,14 \\
Total kg/hari & 12342,4 \\
sisa/tidak terlayani & 0 \\
$\mathrm{~m}^{3} /$ hari & \\
sisa/tidak terlayani & 0 \\
$\mathrm{~kg} /$ hari & \\
\hline
\end{tabular}

Berdasarkan perhitungan tersebut, dapat diketahui bahwa jumlah timbulan sampah di 
Kelurahan Pahandut Kota Palangka Raya sebesar $77,14 \mathrm{~m}^{3} /$ hari atau $12342,4 \mathrm{~kg} /$ hari.

\section{Komposisi Sampah}

$\begin{array}{ccc}\text { Komponen } & \text { komposisi } & \text { sampah } \\ \text { dinyatakan dalam } & \text { persentase } & \text { dengan }\end{array}$ perhitungan sebagai berikut.
$\%$ komponen $=\frac{\text { berat komponen }}{\text { berat total sampah }} \times 100 \%$

Data komposisi sampah Kota Palangka Raya pada tahun 2017-2018 yang diperoleh ditampilkan pada Gambar 2 berikut.

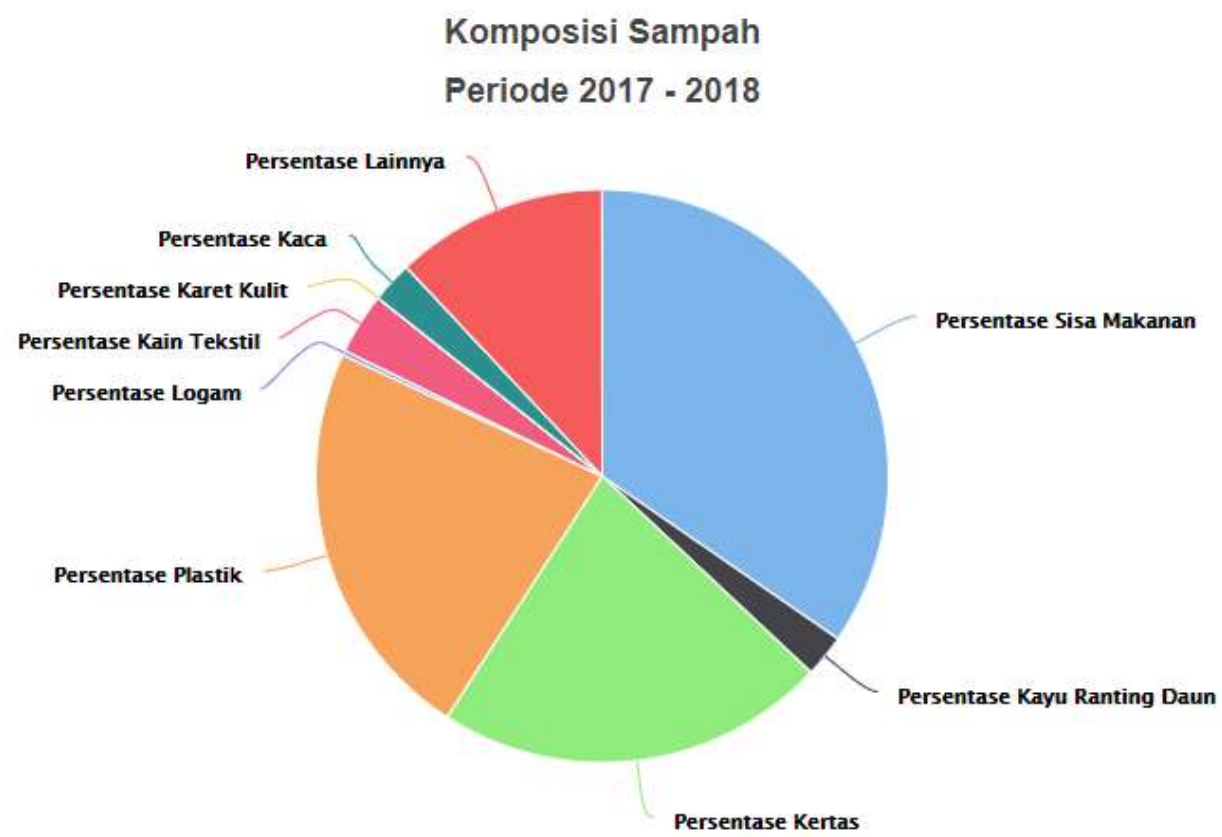

Gambar 2. Komposisi sampah Kota Palangka Raya pada tahun 2017-2018

(Sumber: http://sipsn.menlhk.go.id)

Persentase komposisi sampah Kota Palangka Raya pada tahun 2017-2018 ditunjukkan pada Tabel 3.

Tabel 3. Komposisi sampah Kota Palangka Raya tahun 2017-2018

\begin{tabular}{lc}
\hline \multicolumn{1}{c}{ Sumber sampah } & Persentase $(\%)$ \\
\hline Sisa makanan & 3431 \\
Kayu ranting daun & 236 \\
Kertas & 2193 \\
Plastik & 2264 \\
Logam & 25 \\
Kain tekstil & 344 \\
Karet kulit & 0 \\
Kaca & 231 \\
Lainnya & 1188 \\
\hline
\end{tabular}

Berdasarkan data komposisi sampah tersebut, dapat disimpulkan bahwa sumber sampah terbesar adalah sampah yang berasal dari sisa makanan, yaitu sebesar $3431 \%$ dari total keseluruhan 1338785 ton/hari jumlah timbulan sampah harian ibu kota di Palangka Raya.

\section{Kualitas Air Lindi}

Pemeriksaan kualitas air lindi dilakukan dengan pengukuran konsentrasi parameter $\mathrm{pH}$, Total Dissolved Solid (TDS), Total Suspensed Solid (TSS), Dissolved Oxygen (DO) serta minyak dan lemak. Tabel 4 berikut menunjukkan hasil pemeriksaan kualitas air lindi.

Tabel 4. Hasil pemeriksaan kualitas air lindi

\begin{tabular}{lccc}
\hline Parameter & Satuan & $\begin{array}{c}\text { Hasil } \\
\text { Pengujian }\end{array}$ & Baku Mutu \\
\hline $\mathrm{pH}$ & - & 7,54 & $6,5-9$ \\
TDS & $\mathrm{ppm}$ & 10,12 & 2000 \\
TSS & $\mathrm{mg} \mathrm{L}^{-1}$ & 130 & 100 \\
DO & $\mathrm{mg} \mathrm{L}^{-1}$ & 0,37 & - \\
$\begin{array}{l}\text { Minyak dan } \\
\text { lemak }\end{array}$ & $\mathrm{mg} \mathrm{L}^{-1}$ & $\begin{array}{c}\text { Tidak } \\
\text { terdeteksi }\end{array}$ & 10 \\
\hline
\end{tabular}


Berdasarkan hasil pengujian kualitas air lindi dapat dilihat bahwa air lindi tersebut tidak memenuhi baku mutu sebagai air limbah karena jumlah TSS yang melebihi baku mutu yaitu 130 ppm dari baku mutunya 100 ppm. TSS atau padatan tersuspensi total adalah residu dari padatan total yang tertahan oleh saringan dengan ukuran partikel maksimal 2 mikrometer. Beberapa yang merupakan contoh TSS adalah logam oksida, sulfida, lumpur, tanah liat, ganggang, bakteri dan jamur.

Zat yang tersuspensi biasanya terdiri dari zat organik dan anorganik yang melayang-layang dalam air, secara fisika zat ini sebagai penyebab kekeruhan pada air. Limbah cair dengan konsentrasi zat tersuspensi tinggi tidak boleh dibuang langsung ke badan air karena dapat mempengaruhi kualitas air tanah nantinya.

Air lindi pada masing-masing daerah memiliki karakteristik yang berbeda-beda Pagiling dkk (2017) melaporkan parameter DO, COD, BOD, dan Cd masih memenuhi baku mutu, sedangkan parameter $\mathrm{NO}_{2}$ tidak memenuhi baku mutu di TPA Santiago Tahuna. Pemeriksaan air lindi juga dilakukan Astuti (2006) yang menemukan bahwa parameter BOD, COD, Cd, nitrat, nitrit, serta minyak dan lemak pada air lindi di Tempat Pembuangan Akhir Sampah Putri Cempo Mojosongo Surakarta nilainya cukup tinggi. Karakteristik air lindi yang berbeda-beda ini bergantung pada komposisi sampah dan proses-proses yang terjadi dalam timbulan sampah.

\section{KESIMPULAN}

Jumlah timbulan sampah dan komposisi sampah yaitu $77,14 \mathrm{~m}^{3} /$ hari atau $12342,4 \mathrm{~kg}$ per hari dengan komposisi meliputi sisa makanan, plastik, kertas, kain tekstil, kayu ranting daun, karet kulit dan logam. Kualitas air lindi dengan parameter TSS tidak memenuhi baku mutu serta konsentrasi minyak dan lemak tidak dapat terdeteksi.

\section{UCAPAN TERIMA KASIH}

Ucapan terima kasih disampaikan kepada Kemenristekdikti atas pendanaan pada penelitian ini melalui Hibah Penelitian Dosen
Pemula Tahun Anggaran 2018 berdasarkan Surat Keputusan Lembaga Penelitian dan Pengabdian kepada Masyarakat (LP2M) Universitas Muhammdiyah Palangkaraya dan Surat Perjanjian Kontrak Penelitian bagi Dosen Tetap Universitas Muhammadiyah Palangkaraya Pembiayaan Kemenristekdikti Tahun Anggaran 2018 Nomor: 448.h/PTM.63.R10/LP2M/N/2018.

\section{DAFTAR PUSTAKA}

Badan Standardisasi Nasional, 1995, SNI 193938-1995, Timbulan sampah untuk kota kecil dan sedang di Indonesia, Sekretariat Standardisasi Badan Litbang Kimpraswil, Jakarta.

Harmayani, D. K., Konsukartha, IGM., 2007, Pencemaran Air Tanah Akibat Pembuangan Limbah Domestik di Lingkungan Kumuh Studi Kasus Banjar Ubung Sari, Kelurahan Ubung, Jurnal Permukiman Natah, 5(2), Hal. 93.

Peraturan Menteri Lingkungan Hidup dan Kehutanan Republik Indonesia Nomor P.59/Menlhk/Setjen/Kum. 1/7/2016. Baku Mutu Lindi bagi Usaha dan/atau Kegiatan Tempat Pemrosesan Akhir Sampah.

Pinem, J. A., Ginting, M. S., Peratenta, M., 2014, Pengolahan Air Lindi TPA Muara Fajar dengan Ultrafiltrasi, Jurnal Teknobiologi, 1, Hal 43.

Rahmaniah, R., Meidiana, C., Ari, I. R. D., 2013, Potensi Reduksi Sampah Melalui Pengelolaan Sampah Perkotaan Di TPS Kecamatan Mataram. Jurnal Tata Kota dan Daerah, 5 (5), Hal 119.

Astuti, D., 2006. Analisis Kualitas Air Lindi di Tempat Pembuangan Akhir Sampah Putri Cempo Mojosongo Surakarta. Jurnal Kesehatan, 2(2).

Pagiling, S., Akili, R. H., dan Umboh, J. M. L., 2017. Uji Kualitas Kimia pada Air Lindi di Tempat Pengolahan Akhir Sampah Santiago Tahuna Tahun 2017. Artikel Hasil Penelitian. Fakultas Kesehatan Masyarakat Universitas Sam Ratulangi. 